\title{
Clinical Profile of Patients with Tuberculous Arthritis Admitted in a Tertiary Hospital in the Philippines
}

\author{
Jonnel B. Poblete, MD, ${ }^{1}$ Bernadette Heizel D. Manapat-Reyes, $\mathrm{MD}^{2}$ and Maria Sonia S. Salamat, $\mathrm{MD}^{3}$ \\ ${ }^{1}$ Department of Medicine, Philippine General Hospital, University of the Philippines Manila \\ ${ }^{2}$ Division of Rheumatology, Department of Medicine, Philippine General Hospital, University of the Philippines Manila \\ ${ }^{3}$ Division of Infectious Diseases, Department of Medicine, Philippine General Hospital, University of the Philippines Manila
}

\begin{abstract}
Background. Tuberculous arthritis is a rare extra-pulmonary manifestation of tuberculosis (TB) that can lead to significant disability when left untreated. This study described the clinical profile of patients with TB arthritis admitted in a tertiary hospital in the Philippines.
\end{abstract}

Methods. We reviewed medical records of 65 patients with TB arthritis admitted in the Philippine General Hospital from 2006 to 2019.

Results. Majority of patients were male $(41,63.0 \%)$ and the mean age upon diagnosis was $46.7 \pm 1.7$ years $(20$ 85). Majority (33, 50.8\%) had underlying co-morbidities including hypertension (16, 24.6\%), type 2 diabetes mellitus $(10,15.4 \%)$, and chronic kidney disease $(8,12.3 \%)$. A history of previous TB treatment $(10,15.4 \%)$, intake of immunosuppressive drugs (7, 10.8\%), and trauma on affected joints (13, 20.0\%) were also reported. Majority presented with chronic mono-arthritis (50, 76.9\%) involving the knees $(27,41.5 \%)$ and hips $(21,32.3 \%)$ with a mean duration of symptoms of $20.9 \pm 3.9$ months. The most frequent initial diagnosis upon admission was septic arthritis (21, 32.3\%). Confirmed septic arthritis (10, 15.6\%), pulmonary TB (9, 14.3\%), and disseminated TB (4, 6.3\%) were also observed. Majority were diagnosed based on positive acid-fast bacilli (AFB) smear, polymerase chain reaction (PCR) for Mycobacterium tuberculosis, or synovium biopsy (34, 54.0\%). Anemia (43, 68.3\%) and elevated inflammatory biomarkers (erythrocyte sedimentation rate, ESR [36, 97.3\%] and C-reactive protein, CRP $[40,87 \%])$ were also seen in majority of patients. The most common radiographic findings on $x$-ray were joint space narrowing (42, 84.0\%), soft tissue swelling (22, 44.0\%), and erosions (21, 42.0\%). The mean length of hospital stay was $23.8 \pm 2.8$ days (2-113). Majority underwent surgical interventions $(35,55.6 \%)$ including debridement $(28,80.0 \%)$ and arthrotomy $(25,71.4 \%)$. All received anti-tuberculosis treatment upon diagnosis.

Conclusion. Majority of patients with TB arthritis in this study were male, with mean age in the $5^{\text {th }}$ decade of life,

$2^{\text {nd }}$ Place Oral Presentation, (Descriptive Category) in the Dr. Antonio Gonzaga Memorial Research Forum, 42 ${ }^{\text {nd }}$ Philippine Society for Microbiology and Infectious Diseases Annual Convention, December 4, 2020.

Poster presented in the $22^{\text {nd }}$ Asia-Pacific League of Associations for Rheumatology Virtual Congress, October 24 - 29, 2020.

Poster presented in The Union Asia Pacific Regional Conference Manila on April 23-26, 2019, at the Philippine International Convention Center.

Poster Presentation, European Society of Clinical Microbiology and Infectious Disease Post-graduate Education Course: Tuberculosis and Mycobacterial Infections, An Educational Update on September 26 -29, 2018, at the National University of Singapore.

Corresponding author: Jonnel B. Poblete, MD, PhD Department of Medicine

Philippine General Hospital, University of the Philippines Manila Taft Avenue, Manila 1000, Philippines

Email: jbpoblete1@up.edu.ph presenting with mono-arthritis, anemia, elevated inflammatory markers, and radiologic findings of joint narrowing. All patients received medical treatment while more than half underwent surgery. There should be a high index of suspicion for TB arthritis in a patient from an endemic country presenting with chronic monoarthritis in weight-bearing joints to prevent delay in diagnosis and significant joint destruction and disability.

Key Words: TB, arthritis

\section{INTRODUCTION}

Tuberculosis (TB) remains a major public health problem that affected around 10 million people worldwide in 2019. The Philippines is a high TB burden country with one of the highest estimated number of new TB and drug-resistant TB cases worldwide. ${ }^{1}$ 
TB arthritis is an uncommon extrapulmonary manifestation of TB that could lead to significant joint destruction and disability. ${ }^{2,3}$ Diagnosis of TB arthritis is usually delayed due to its indolent nature, lack of systemic or pulmonary involvement, and absence of specific radiographic findings. ${ }^{4,5}$

Despite the prevalence of TB in the Philippines, there is paucity of data regarding the clinical picture of TB arthritis in the Philippines. Only one cohort of Filipino patients with TB arthritis was described in the literature. ${ }^{6}$ Thus, this study aims to describe the clinical profile of patients with TB arthritis admitted in a tertiary hospital in the Philippines.

\section{METHODS}

\section{Study Design and Study Setting}

We conducted a medical record review using a descriptive and retrospective design. This study was done at the Philippine General Hospital (PGH), the national university and referral hospital in the Philippines.

\section{Study Population and Case Definition}

We included patients 19 years old and above admitted in the PGH from 2006 to 2019 with TB arthritis. TB arthritis was diagnosed based on any of the following: 1) identification of $M$. tuberculosis from affected joint by direct microscopy, culture, or polymerase chain reaction (PCR); 2) evidence of caseating granuloma on synovium biopsy; or 3) clinical diagnosis based on clinical presentation, radiographic findings, and/or response to anti-TB medications.

\section{Sampling Design, Data Collection and Statistical Analysis}

Convenience sampling was utilized. Patients were identified retrospectively from the patient census/database of the Division of Rheumatology, Division of Infectious Diseases and the Medical Records Section of PGH. Medical records were reviewed for demographic data, detailed clinical history and physical examination, laboratory investigations performed, and the patient's clinical course. Data were collected on a standard data collection form, computerized and encoded using Microsoft Excel. Statistical analysis was done using STATA version 14 (StataCorp, LP, College Station, TX). Continuous data were presented as mean \pm $\mathrm{SD}$ and categorical data as percentages.

\section{Ethical Considerations}

The study was approved by the University of the Philippines Manila Research Ethics Board (UPMREB 2016-190-01) last March 18, 2020.

\section{RESULTS}

\section{Baseline Characteristics}

We included 65 adult patients with TB arthritis admitted in the PGH from 2006 to 2019 in the study. Majority were

Table 1. Baseline characteristics of the study population $(\mathrm{N}=65)$

Baseline Characteristics

Age [Mean \pm SD (Range)], years

20-29

30-39

40-49

50-59

60 and older

\begin{tabular}{lc}
\hline Male & $41(63.0)$ \\
\hline Previous TB treatment & $10(15.4)$ \\
\hline Trauma on affected joint/s & $13(20.0)$ \\
\hline Immunosuppressive therapy & $7(10.8)$ \\
\hline Co-morbidities & $33(50.8)$ \\
Hypertension & $16(24.6)$ \\
Type 2 diabetes mellitus & $10(15.4)$ \\
Chronic kidney disease & $8(12.3)$ \\
Gouty arthritis & $5(7.7)$ \\
Bronchial asthma & $4(6.2)$ \\
Malignancy & $3(4.6)$ \\
Systemic lupus erythematosus & $2(3.1)$ \\
Cardiovascular disease & $1(1.5)$ \\
Rheumatoid arthritis & $1(1.5)$ \\
Dermatomyositis with scleroderma overlap & $1(1.5)$ \\
HIV & $1(1.5)$ \\
\hline
\end{tabular}

male (63.0\%) and the mean age upon diagnosis was $46.6 \pm 1.7$ years. A history of previous TB treatment (15.4\%), intake of immunosuppressive drugs (10.8\%), trauma on affected joints (20.0\%) and co-morbid conditions (50.8\%) were reported. The most commonly reported co-morbid conditions were hypertension (24.6\%), type 2 diabetes mellitus (15.4\%), and chronic kidney disease (12.3\%). Rheumatologic disorders, including gouty arthritis (7.7\%), SLE (3.1\%), rheumatoid arthritis $(1.5 \%)$ and dermatomyositis with scleroderma $(1.5 \%)$, were also reported (Table 1$)$.

\section{Clinical Presentation}

Majority of the patients presented with chronic monoarthritis (76.9\%) with a mean duration of symptoms of $20.9 \pm 3.9$ months (Range: $0.25-180$ ). The most commonly involved joints were the knees (41.5\%) and the hips (32.3\%). The most common local symptoms were limitation in range of motion (ROM) (98.4\%) and soft tissue swelling (46.2\%). Systemic symptoms, such as fever (21.5\%), weight loss (15.4\%), and malaise (6.2\%), were less commonly observed. The most common initial diagnosis upon admission was septic arthritis (32.3\%). However, only 10 patients (15.6\%) had confirmed septic arthritis. Nine patients (14.3\%) also had concomitant PTB while four had disseminated TB (6.3\%).

More than half (53.9\%) of the TB arthritis diagnosis was confirmed bacteriologically with a positive AFB smear on synovial fluid/tissue/aspirate (33.3\%), biopsy result showing chronic granulomatous inflammation with Langhans type giant cells (14.3\%), or a positive PCR for M. tuberculosis (12.7\%); the rest (46.0\%) were diagnosed clinically. Anemia, predominantly normocytic, normochromic, was a 
Table 2. Clinical and diagnostic profile of patients with TB arthritis $(N=65)$

\begin{tabular}{|c|c|}
\hline Profile & $n(\%)$ \\
\hline $\begin{array}{l}\text { Clinical presentation } \\
\text { Chronic mono-arthritis } \\
\text { Acute mono-arthritis } \\
\text { Chronic oligo-arthritis } \\
\text { Acute oligo-arthritis } \\
\text { Chronic polyarthritis }\end{array}$ & $\begin{array}{l}50(76.9) \\
7(10.8) \\
4(6.2) \\
3(4.6) \\
1(1.5)\end{array}$ \\
\hline $\begin{array}{l}\text { Duration of symptoms, in months } \\
\text { [Mean } \pm S D \text { (Range)] }\end{array}$ & $20.9 \pm 3.9(0.25-180)$ \\
\hline $\begin{array}{l}\text { Chronicity } \\
\text { Acute ( } \leq 6 \text { weeks) } \\
\text { Chronic (> } 6 \text { weeks) }\end{array}$ & $\begin{array}{l}10(15.4) \\
55(84.6)\end{array}$ \\
\hline $\begin{array}{l}\text { Number of joints involved } \\
\text { Mono-arthritis (1) } \\
\text { Oligo-arthritis }(2-3) \\
\text { Polyarthritis }(\geq 4) \\
\end{array}$ & $\begin{array}{c}57(87.7) \\
7(10.8) \\
1(1.5) \\
\end{array}$ \\
\hline $\begin{array}{l}\text { Joint Involvement } \\
\text { Knee } \\
\text { Hip } \\
\text { Ankle } \\
\text { Wrist } \\
\text { Elbow } \\
\text { Shoulder } \\
\text { Proximal interphalangeal joint }\end{array}$ & $\begin{aligned} & 27(41.5) \\
& 21(32.3) \\
& 12(18.5) \\
& 6(9.2) \\
& 2(3.1) \\
& 2(3.1) \\
& 2(3.1) \\
&\end{aligned}$ \\
\hline $\begin{array}{l}\text { Associated symptoms } \\
\text { Limitation in ROM } \\
\text { Soft tissue swelling } \\
\text { Draining sinus/Abscess } \\
\text { Fever } \\
\text { Weight loss } \\
\text { Malaise }\end{array}$ & $\begin{array}{c}64(98.4) \\
30(46.2) \\
17(26.2) \\
14(21.5) \\
10(15.4) \\
4(6.2)\end{array}$ \\
\hline $\begin{array}{l}\text { Initial diagnosis } \\
\text { Septic arthritis } \\
\text { TB arthritis } \\
\text { Avascular necrosis } \\
\text { Chronic osteomyelitis } \\
\text { Soft tissue mass } \\
\text { Gouty arthritis } \\
\text { Osteoarthritis } \\
\text { Bursitis } \\
\text { Charcot foot } \\
\text { Bone cancer } \\
\text { Deep space infection } \\
\text { Post traumatic arthritis } \\
\text { Rheumatoid arthritis } \\
\text { SLE arthritis }\end{array}$ & $\begin{array}{c}21(32.3) \\
10(15.4) \\
7(10.8) \\
6(9.2) \\
6(9.2) \\
5(7.7) \\
3(4.6) \\
1(1.5) \\
1(1.5) \\
1(1.5) \\
1(1.5) \\
1(1.5) \\
1(1.5) \\
1(1.5)\end{array}$ \\
\hline
\end{tabular}

\begin{tabular}{lc}
\multicolumn{1}{c}{ Profile } & $\mathbf{n}(\%)$ \\
\hline Confirmed septic arthritis $(\boldsymbol{n}=64)$ & $10(15.6)$ \\
\hline Concomitant PTB $(\boldsymbol{n}=63)$ & $9(14.3)$ \\
\hline Concomitant disseminated TB $(\boldsymbol{n}=63)$ & $4(6.3)$ \\
\hline Diagnosis of TB arthritis $(\boldsymbol{n}=63)$ & \\
Clinical & $29(46.0)$ \\
Bacteriologically-confirmed & $34(53.9)$ \\
Acid-fast bacilli positive & $21(33.3)$ \\
Biopsy-confirmed & $9(14.3)$ \\
MTB detected by PCR & $8(12.7)$ \\
\hline Laboratory findings & \\
Anemia ( $\mathrm{n}=63)$ & $43(68.3)$ \\
Elevated WBC ( $\mathrm{n}=63)$ & $12(19.05)$ \\
Elevated ESR $(\mathrm{n}=37)$ & $36(97.3)$ \\
Mean ESR \pm SD (Range) & \\
Elevated CRP $(\mathrm{n}=46)$ & $40(87.0)$ \\
\hline Radiographic findings $(\boldsymbol{n}=50)$ & \\
Joint space narrowing & $42(84.0)$ \\
Soft tissue swelling & $22(44.0)$ \\
Erosions & $21(42.0)$ \\
Lytic lesions & $17(34.0)$ \\
Osteopenia & $11(22.0)$ \\
Sclerosis & $10(20.0)$ \\
Sequestrum & $2(4.0)$ \\
\hline
\end{tabular}

TB, tuberculosis; ROM, Range of motion; ESR, Erythrocyte sedimentation rate; $C R P, C$-reactive protein

areas. Computed tomography (CT) scan was also done in one patient revealing multiple osseous lytic lesions and bony defects (Table 2).

\section{Clinical course}

The mean length of hospital stay of patients admitted for TB arthritis was $23.8 \pm 2.8$ days $(2-113)$. Surgical intervention was performed in majority of patients $(55.6 \%)$. The most common surgical procedures performed were debridement (80\%) and arthrotomy (71.4\%). All patients received standard anti-TB therapy during admission. Three patients (4.8\%) developed mild adverse drug event (cutaneous rash) upon administration of anti-TB medications. No mortality was reported among patients admitted for TB arthritis (Table 3).

frequent finding (68.3\%). Elevated inflammatory markers, such as ESR (36/37, 97.3\%) and CRP (40/46, 87.0), were also documented in majority of patients. The most common radiographic findings on $\mathrm{x}$-ray were joint space narrowing (42, 84.0\%), soft tissue swelling (22, 44.0\%), and erosions (21, 42.0\%). Nine patients each had different MRI findings namely: 1) bright signals, irregular cortical defects, subluxation and narrowing; 2) progressive erosive changes; 3) cystic focus, osteomyelitis, tenosynovitis, anterolateral fluid collection; 4) synovial thickening; 5) avascular necrosis; 6) synovitis; 7) cortical destruction; 8) abnormal marrow signal; and 9) non-specific findings. Two patients underwent bone scan which showed increased activity on the affected

Table 3. Clinical course of patients with TB arthritis $(N=65)$

\begin{tabular}{lc}
\multicolumn{1}{c}{ Clinical Course } & $\mathrm{n}(\%)$ \\
\hline Length of hospital stay, days & $23.8 \pm 2.8(2-113)$ \\
[Mean \pm SD (Range)] & \\
\hline Surgical intervention $(\mathbf{n}=35)$ & $28(80.0)$ \\
Debridement & $25(71.4)$ \\
Arthrotomy & $9(25.7)$ \\
Synovectomy & $9(25.7)$ \\
Arthroplasty & $2(5.7)$ \\
Osteotomy & $1(2.9)$ \\
Incision and drainage & $1(2.9)$ \\
Sequestrectomy & $63(100.0)$ \\
\hline Received anti-tuberculous medications $(\boldsymbol{n}=63)$ & $3(4.8)$ \\
Developed ADE & \\
\hline
\end{tabular}




\section{DISCUSSION}

Similar to previous studies done in Thailand, Taiwan, and the United States, TB arthritis was commonly observed among the older population ${ }^{2,3,7,8}$, male $\mathrm{sex}^{3}$, and those with underlying rheumatologic disease and immunocompromised conditions. ${ }^{7-9}$ The mean duration between onset of symptoms and consult was almost 21 months compared to the Thailand cohort that reported a mean duration of 25.4 months. ${ }^{3}$ The delay in the diagnosis may be attributed to the chronic and indolent nature of the disease and/or our patient's poor health-seeking behavior; this is comparable to previous literature showing long duration between symptom onset and diagnosis., ${ }^{2,3}$ Other pertinent information on the patient's clinical history such as intake of immunosuppressive therapy, history of trauma in affected joint/s, and previous TB treatment should also be sought since they may predispose a patient to TB.

Similar to previous studies, chronic monoarthritis was the most common presentation., ${ }^{2,3,9}$ However, acute arthritis was also observed in some patients especially among those aged 50 and above and those with concomitant rheumatologic diseases (SLE and septic arthritis) consistent with other studies. ${ }^{2,3}$ Our study observed fewer polyarticular involvement compared to Thailand where 30\% showed polyarticular involvement. We only had 1 patient with polyarticular involvement and this patient had disseminated TB. ${ }^{3}$ We also observed fewer oligoarticular involvement compared to a previous study in the Philippines. ${ }^{6}$

The most commonly observed local symptoms were limitation in ROM and soft tissue swelling. However, abscess and sinus tract formation were also seen especially among those presenting with chronic arthritis. On the other hand, systemic symptoms, such as fever, weight loss, and night sweats, were not commonly reported compared to a study in Netherlands, where systemic symptoms were frequently observed. ${ }^{10}$

Compatible with previous literature, our study also showed that the weight-bearing joints, such as knees and hips, were most commonly involved in TB arthritis. ${ }^{2,3,6,10,11}$ This is also similar to the previous cohort of Filipino patients with TB arthritis where monoarthritis of the knees was predominant. ${ }^{6}$ However, we have also observed TB arthritis in less typical areas such as the small joints of the hands, elbow, and shoulder.

Septic arthritis was the most common initial diagnosis upon consult; however, we only observed bacteriologicallyconfirmed septic arthritis on top of TB arthritis in 10 patients. Since both TB arthritis and septic arthritis can present acutely, every attempt to determine the etiology of the inflamed joint should be made. However, the low rate of positivity of synovial fluid and/or tissue for acid-fast staining remains a challenge. ${ }^{4,7}$ Although a synovial fluid aspirate or tissue is easier to collect than synovium biopsy, histopathologic evidence of TB still remains the gold standard in the diagnosis of TB arthritis. Nucleic acid amplification test for TB may also be done to confirm the diagnosis.

Ancillary studies such as $\mathrm{CBC}$ and inflammatory markers may also be useful. Our study showed that majority of patients had normocytic, normochromic anemia and elevated ESR and CRP. This reflects the ongoing inflammation occurring in the joints. Despite a previous report in Thailand where blood eosinophilia was present in more than half of the population, only one patient in our study showed elevated blood eosinophil level. Imaging of the affected joint/s should also be done promptly in all patients. Radiographic findings on $\mathrm{x}$-ray commonly seen were joint space narrowing, soft tissue swelling, and erosions consistent with previous literature. ${ }^{12,13}$ However, these radiographic findings are non-specific and may also occur in other inflammatory arthritis.

When diagnostic tests yield negative results, the diagnosis of TB arthritis can still be made with a detailed history taking, physical examination, and laboratory tests/ radiographic imaging. In this study, majority of those with clinically diagnosed TB arthritis also presented with chronic mono-arthritis predominantly affecting the knees and the hips. All presented with limitation in ROM while systemic symptoms were less frequent. Anemia, elevated inflammatory markers, and typical radiographic findings were also observed. Interestingly, all patients diagnosed with disseminated TB arthritis in the study had clinically diagnosed TB arthritis. Thus, the presence of an inflamed joint, in the background of $\mathrm{TB}$ affecting other organ system/s, makes TB arthritis the most likely diagnosis.

Due to the indolent nature of this disease, majority of our patients already presented with significant joint damage on admission requiring prompt surgical intervention such as debridement, arthrotomy, synovectomy, and arthroplasty; this is in comparison with a previous study done in the Philippines where only $6 \%$ underwent surgical intervention. ${ }^{6}$ Hospital stay was also prolonged, with an average of 24 days, likely from the delayed diagnosis and initiation of treatment.

\section{CONCLUSION}

This is the largest cohort of TB arthritis patients described in the Philippines. TB arthritis commonly presents with chronic mono-arthritis involving the knees and the hips associated with local symptoms of inflammation. Anemia and elevated inflammatory markers were commonly present while radiographic findings mostly revealed non-specific joint space narrowing and erosions.

There should be a high index of suspicion for TB arthritis in any inflamed joint among patients living in endemic countries such as the Philippines. Early recognition may lead to prompt treatment with anti-tuberculosis medications and/or surgical interventions for patients already presenting with significant joint destruction. 


\section{Statement of Authorship}

All authors participated in the data collection and analysis, and approved the final version submitted.

\section{Author Disclosure}

All authors declared no conflicts of interest.

\section{Funding Source}

This paper was self-funded.

\section{REFERENCES}

1. World Health Organization. World TB Report. [Internet] 2020 [cited 2006 Dec]. Available from http://www.who.int/tb/publications/ global_report/en/

2. Huang TY, Wu TS, Yang CC, Chiang PC, Yu KH, Lee MH. Tuberculous arthritis - a fourteen-year experience at a tertiary teaching hospital in Taiwan. J Microbiol Immunol Infect. 2007; 40:493-9.

3. Foocharoen C, Nanagara R, Foocharoen T, Mootsikapun P, Suwannaroj S, Mahakkanukrauh A. Clinical features of tuberculous septic arthritis in Khon Kaen, Thailand: A 10-year retrospective study. SE Asian J Trop Med Pub Health. 2010; 41(6):1438-46.
4. Al-Sayyad MJ, Abumunaser LA. Tuberculous arthritis revisited as a forgotten cause of monoarticular arthritis. Ann Saudi Med. 2011; 31(4):398-401.

5. Tseng CC, Huang RM, Chen KT. Tuberculosis arthritis: Epidemiology, diagnosis, treatment. Clin Res Foot Ankle. 2014; 2:131.

6. Victorio-Navarra ST, Torralba TP and Ngo DC. Clinical profile of tuberculous arthritis at a University Hospital. Phil J Int Med 1995; 33:37-40.

7. Deesomchok U, Tumrasvin T. Clinical features of tuberculous arthritis. J Med Assoc Thai. 1998; 71:496-500.

8. Rieder HL, Snider DE Jr, Cauthen GM. Extrapulmonary tuberculosis in the United States. Am Rev Respir Dis. 1990; 141:347-51.

9. Berney S, Goldstein M, Bishko F. Clinical and diagnostic features of tuberculous arthritis. Am J Med. 1972; 53:36-42.

10. Jutte PC, van Loenhout-Rooyackers JH, Borgdorff MW, van Horn JR. Increase of bone and joint tuberculosis in The Netherlands. Bone Joint J. 2004; 86(6):901-4.

11. Sequeira W, Co H, Block JA. Osteoarticular tuberculosis: current diagnosis and treatment. Am J Ther. 2000; 7:393-8.

12. Burril J, Williams C, Brain G, Conder G, Hine AL, Misra RR. Tuberculosis: a radiologic review. Radiographics. 2007; 27(5):1255-73.

13. Phemister, DB, Hatcher, CH. Correlation of pathological and roentgenological findings in the diagnosis of tuberculous arthritis. Am J Roentgenol. 1933; 29:736.
The Acta Medica Philippina is now accepting original scientific papers, review articles and case reports for its upcoming issues. Please follow the format for submission as indicated in the "Instructions to Authors" elsewhere in the journal. All papers received shall be properly acknowledged. For inquiries and submission of proposals, please email us at actamedicaphilippina.upm@up.edu.ph 